\title{
Therapeutic efficacy of Schistosoma japonicum cystatin on sepsis-induced cardiomyopathy in a mouse model
}

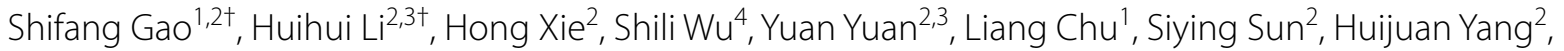 \\ Lingqin Wu ${ }^{2}$, Yongsheng Bai ${ }^{2}$, Qiao Zhou ${ }^{2}$, Xin Wang ${ }^{2}$, Bin Zhan ${ }^{5}$, Hu Cui $^{*}$ and Xiaodi Yang ${ }^{2,3^{*}}$
}

\begin{abstract}
Background: Myocardial dysfunction is one of the most common complications of multiple organ failure in septic shock and significantly increases mortality in patients with sepsis. Although many studies having confirmed that helminthderived proteins have strong immunomodulatory functions and could treat inflammatory diseases, there is no report on the therapeutic effect of Schistosoma japonicum-produced cystatin (Sj-Cys) on sepsis-induced cardiac dysfunction.

Methods: A model of sepsis-induced myocardial injury was established by cecal ligation and puncture (CLP) in mice. Upon CLP operation, each mouse was intraperitoneally treated with $10 \mu \mathrm{g}$ of recombinant Sj-Cys (rSj-Cys). Twelve hours after CLP, the systolic and diastolic functions of the left ventricular were examined by echocardiography. The levels of myoglobin (Mb), cardiac troponin I (cTnl), N-terminal pro-Brain Natriuretic peptide (NT-proBNP) in sera, and the activity of myeloperoxidase (MPO) in cardiac tissues were examined as biomarkers for heart injury. The heart tissue was collected for checking pathological changes, macrophages and pro-inflammatory cytokine levels. To address the signaling pathway involved in the anti-inflammatory effects of rSj-Cys, myeloid differentiation factor 88 (MyD88) was determined in heart tissue of mice with sepsis and LPS-stimulated H9C2 cardiomyocytes. In addition, the therapeutic effects of rSj-Cys on LPS-induced cardiomyocyte apoptosis were also detected. The levels of M1 biomarker iNOS and M2 biomarker Arg-1 were detected in heart tissue. The pro-inflammatory cytokines TNF-a and IL-6, and regulatory cytokines IL-10 and TGF- $\beta$ were measured in sera and their mRNA levels in heart tissue of rSj-Cys-treated mice.
\end{abstract}

Results: After rSj-Cys treatment, the sepsis-induced heart malfunction was largely improved. The inflammation and injury of heart tissue were significantly alleviated, characterized as significantly decreased infiltration of inflammatory cells in cardiac tissues and fiber swelling, reduced levels of Mb, cTnl and NT-proBNP in sera, and MPO activity in heart tissue. The therapeutic efficacy of rSj-Cys is associated with downregulated pro-inflammatory cytokines (TNF- $a$ and IL-6) and upregulated regulatory inflammatory cytokines (IL-10 and TGF- $\beta$ ), possibly through inhibiting the LPS-MyD88 signal pathway.

Conclusions: RSj-Cys significantly reduced sepsis-induced cardiomyopathy and could be considered as a potential therapeutic agent for the prevention and treatment of sepsis associated cardiac dysfunction.

Keywords: Cystatin, Schistosoma japonicum, Myocardial dysfunction, Immunoregulation

\footnotetext{
*Correspondence: Ch81598159@163.com;yxd_qf@163.com

†Shifang Gao and Huihui Li contributed equally to this work

${ }^{1}$ Second Affiliated Hospital of Bengbu Medical College, Bengbu 233000,

China

${ }^{2}$ Anhui Key Laboratory of Infection and Immunity of Bengbu Medical

College, Bengbu 233000, China

Full list of author information is available at the end of the article
}

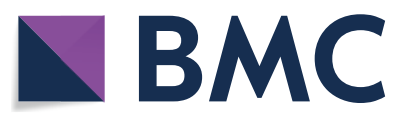

(c) The Author(s) 2020. This article is licensed under a Creative Commons Attribution 4.0 International License, which permits use, sharing, adaptation, distribution and reproduction in any medium or format, as long as you give appropriate credit to the original author(s) and the source, provide a link to the Creative Commons licence, and indicate if changes were made. The images or other third party material in this article are included in the article's Creative Commons licence, unless indicated otherwise in a credit line to the material. If material is not included in the article's Creative Commons licence and your intended use is not permitted by statutory regulation or exceeds the permitted use, you will need to obtain permission directly from the copyright holder. To view a copy of this licence, visit http://creativeco mmons.org/licenses/by/4.0/. The Creative Commons Public Domain Dedication waiver (http://creativecommons.org/publicdomain/ zero/1.0/) applies to the data made available in this article, unless otherwise stated in a credit line to the data. 


\section{Background}

Sepsis is a life-threatening organ dysfunction caused by serious infection, affecting the lives of millions of people around the world $[1,2]$. Myocardial dysfunction is a common complication of hospitalized sepsis patients, and myocardial depression occurs in $40-50 \%$ of patients with sepsis [3, 4]. Septic myocardial dysfunction is associated with overproduction of pro-inflammatory cytokines, including IL- 6 and TNF- $\alpha$, which play pivotal roles in cardiomyocyte apoptosis and injury $[3,5]$. In recent years, studies have suggested that sepsis-induced cardiac dysfunction, the major cause of sepsis mortality (70-90\%) [6], is caused by myocardial apoptosis mediated by the MyD88 signal pathway that activates and over-expresses a variety of pro-inflammatory cytokines, including TNF- $\alpha$ and IL-6 [7]. At present, the control of sepsis-induced cardiac failure depends on drug therapies. The most commonly used drugs for the treatment of sepsis-induced cardiac dysfunction are glucocorticoid, norepinephrine, low molecular weight heparin and antibiotics. Although these drugs are capable of preventing the development of inflammation, activating the anticoagulation system, enhancing anti-inflammatory function, or suppressing the bacterial proliferation, there is still a proportion of patients who cannot survive from severe sepsis. Other alternative approaches to better control sepsis and reduce sepsis-related myocardial dysfunction is greatly needed.

Parasitic helminths co-evolve with mammalian hosts and develop some strategies to survive within hosts. These strategies include modulating the host immune system to downregulate the immune response to helminths (parasite-specific immunomodulation) [8], characterized by a dominant Th2-mediated immune response and activated regulatory $\mathrm{T}$ cells (Tregs) or monocyte responses [9-11]. The helminth-induced regulatory responses not only facilitate the survival of worms in the host, but also benefit the host to reach immune homeostasis between the resistance and tolerance and reduce immunopathology [12]. Helminth infection induced alternately activated macrophages (AAM) [13] and Tregs play important roles in the control of inflammation and tissue repair [13-15]. Further evidence showed that helminth-secreted proteins can induce the host to actively produce immune regulation $[16,17]$. Due to their potent immunomodulatory functions, helminth infections or helminth-derived or secreted proteins, have been used as therapeutic regents to treat some immunno-inflammatory diseases such as allergies and autoimmune disorders [18-20]. In particular, cystatins derived from various parasitic helminths have received most of the attention because they have been identified as strong immunomodulatory proteins [14] and successfully used as potential therapeutic agents for inflammatory and autoimmune diseases [21-25]. Parasitic helminth cystatins have been demonstrated to ameliorate arthritis, asthma and colitis $[14,22,24,25] . \mathrm{Sj}$-Cys is a cysteine protease inhibitor (cystatin) derived from the blood-feeding trematode Schistosoma japonicum [26]. Treatment with $\mathrm{rSj}$-Cys significantly stimulated Tregs and inhibited the antigenpresenting functions of dendritic cells (DCs) [27]. It also inhibited the release of pro-inflammatory factors (TNF- $\alpha$, IL-6) in LPS-stimulated macrophages [23]. Recombinant $\mathrm{Sj-Cys}$ has been used as a therapeutic agent to alleviate the severity of dextran sulfate sodium (DSS)-induced colitis in mice [21] and murine collagen-induced arthritis [22]. Our previous study has identified that $\mathrm{rSj}$-Cys displayed the therapeutic effect of cecal ligation and puncture (CLP)-induced bacterial sepsis characterized by the increased survival rates, alleviated overall disease severity and tissue injury of liver, kidney and lungs [12]. These therapeutic effects are associated with downregulation of pro-inflammatory cytokines and upregulation of regulatory cytokines [12].

In this study, we explore the therapeutic effect of $\mathrm{rSj}$ Cys on sepsis-triggered cardiac dysfunction and we found that treatment with $\mathrm{rSj}$-Cys significantly reduced the sepsis-induced cardiomyopathy and heart injury in a mouse model, providing an alternative approach to control sepsis-induced heart failure and death.

\section{Methods \\ Production of recombinant Sj-Cys}

DNA coding for $\mathrm{Sj}$-Cys was cloned in-frame into pET28a and the sequencing confirmed recombinant plasmid DNA with correct insert was transformed into E. coli BL21 using the calcium transfection method. The recombinant $\mathrm{Sj}$-Cys (rSj-Cys) with a His-tag at the $\mathrm{N}$-terminus was induced with $1 \mathrm{mM}$ isopropylthio- $\beta$-galactoside (IPTG; Sigma-Aldrich, Steinheim, Germany) at $37^{\circ} \mathrm{C}$ for $5 \mathrm{~h}$, and purified from the soluble fraction of the induced bacteria using a HisPur ${ }^{\mathrm{TM}} \mathrm{Ni}$-NTA Spin Column (Thermo Fisher Scientific Inc., Waltham, USA). The contaminated endotoxin was removed from the purified recombinant protein using a ToxOut ${ }^{\mathrm{TM}}$ High Capacity Endotoxin Removal Kit (BioVision, Palo Alto, California, USA) and the residual endotoxin level was measured using a ToxinSensor ${ }^{\mathrm{TM}}$ Chromogenic Limulus Amebocyte Lysate (LAL) Endotoxin Assay Kit (GenScript Biotechnology, Nanjing, China) following the manufacturer's protocol. The concentration of $\mathrm{rSj}$-Cys was measured using a Bicinchoninic Acid Protein Assay Kit (Beyotime Biotechnology, Shanghai, China) and the recombinant protein stored at $-80{ }^{\circ} \mathrm{C}$ until use. 


\section{Animals}

Specific pathogen-free (SPF) 6-8-week-old male BALB/c mice (body weight of 20-22 g) were purchased from Anhui Medical University Experimental Animal Facility (approval no. AMU26-08061). The mice were housed in a climate-controlled facility maintained at $23 \pm 1{ }^{\circ} \mathrm{C}$, $55 \pm 5 \%$ humidity with a $12 \mathrm{~h}$ light/dark photocycle and ad libitum access to food and water.

\section{Sepsis-induced cardiomyopathy}

The mice were subjected to CLP surgery according to the method described previously [4]. Briefly, mice were fasted for $12 \mathrm{~h}$, with only drinking water available, and then anesthetized by intraperitoneal injection of $0.2 \mathrm{ml} / 20 \mathrm{~g}$ of $4 \%$ chloral hydrate. Following a $1-2 \mathrm{~cm}$ midline laparotomy incision, $66 \%$ of the cecum was ligated with a 4-0 silk suture (Syneture, Norwalk, CT). A through-andthrough puncture was made on the anti-mesenteric side with an 18-gauge needle and a small amount of feces was extruded through the puncture holes to ensure perforation. The cecum was placed back in its original location and the abdomen was closed in two layers with 4-0 silk (Syneture). Following CLP, sterile normal saline $(300 \mu \mathrm{l})$ was injected sub-dermally for fluid resuscitation. Sham mice underwent the above process except for CLP.

\section{Treatment of sepsis-induced cardiomyopathy with rSj-Cys} A total of 6 CLP-operated mice were treated intraperitoneally with $10 \mu \mathrm{g}$ of $\mathrm{rSj}$-Cys in a total volume of $200 \mu \mathrm{l}$ $30 \mathrm{~min}$ after surgery. The same number of CLP-operated mice were given $200 \mu \mathrm{l}$ of PBS only as a control. As normal controls, 12 mice that underwent sham surgery were divided into two groups; 6 received the same amount of rSj-Cys and 6 received PBS only. Twelve hours later, all mice were measured for echocardiography. Blood was collected from each mouse under anesthesia and sera were centrifuged at $3000 \times \mathrm{rpm}$ for $15 \mathrm{~min}$ at $4{ }^{\circ} \mathrm{C}$ and stored at $-80{ }^{\circ} \mathrm{C}$ until use. All mice were euthanized and hearts collected for histopathological staining and measurement.

\section{Echocardiography}

Echocardiographic evaluation was performed using a high-resolution echocardiograph (Vevo 2100; VisualSonics, Toronto, Canada) for the differently treated mice groups. Briefly, a mixture of $1 \%$ isoflurane and oxygen was inhaled via a nose cone, and each mouse was carefully kept under mild anesthesia and subjected to M-mode and Doppler echocardiography according to the method described previously [28]. The ejection fraction (EF\%) and fractional shortening (FS\%) of the left ventricle were calculated from M-mode tracing to reflect left systolic function. Peak early-diastolic transmitral velocities
(E wave) and peak late-diastolic transmitral velocities (A wave) across the mitral valve inflow were examined on Doppler flow tracings and were used to calculate E/A ratios, a commonly used parameter of left ventricular diastolic function. All echocardiographic procedures were performed by the same skilled operator and data averaged from at least three consecutive cardiac cycles.

\section{Histological examination of myocardium}

Mouse hearts collected from different experimental groups were fixed in $4 \%$ buffered paraformaldehyde for $12 \mathrm{~h}$. Fixed left heart ventricles were sectioned and stained with hematoxylin and eosin $(H \& E)$ stain. $H \& E$ stained sections were observed under light microscopy (200× magnification) (Nikon, Tokyo, Japan) for pathological changes.

\section{Biochemical analysis}

The heart-released myoglobin $(\mathrm{Mb})$, cardiac troponin I (cTnI) and N-terminal pro-Brain Natriuretic peptide (NT-proBNP) in sera, and myeloperoxidase (MPO) in heart tissue, were measured as biochemical markers for heart injury. The levels of cTnI and NT-proBNP in sera were detected using an enzyme-linked immunosorbent assay (ELISA) kit (Elabscience Biotechnology Co., Ltd, Wuhan, China). The concentration of Mb was measured in the mouse sera using a Fully Automated Biochemistry Analyzer (Beckman Coulter, Brea, California, USA). The heart tissue was weighed and homogenized, the MPO activity in the homogenate was determined using a MPO test kit (Bioenginering Institute, Nanjing, China).

\section{Detection of IL- 6 , TNF- $\alpha$, TGF- $\beta$ and IL-10 in sera and cell supernatants}

The concentration of pro-inflammatory (TNF- $\alpha$ and IL-6) and regulatory (IL-10 and TGF- $\beta$ ) cytokines in cell culture supernatants and experimental mouse sera were detected by ELISA in accordance with the manufacturer's instructions (ABclonal Biotechnology Co., Ltd. Wuhan, China).

\section{Detection of cardiac TNF- $\alpha$, IL-6, IL-10, TGF- $\beta$, iNOS and Arg-1 mRNA expression by quantitative real time PCR (qRT-PCR)}

Total RNA from the left ventricular myocardium was extracted with QIAzol reagent (Ambion, Austin, TX, USA). Then cDNAs were reverse-transcribed from $2 \mu \mathrm{g}$ total RNA using a reverse transcription kit (RevertAid First Strand cDNA Synthesis Kit; Thermo Fisher Scientific Inc.). The cDNA was used as a template for qRTPCR using the SYBR Green Super Mix Kit (Takara Bio Inc., Tokyo, Japan). All samples were duplicated and the 
qRT-PCR signal of the target transcript in the treated group was compared with the control housekeeper gene (GAPDH) signal by relative quantification. The $2^{-\Delta \Delta \mathrm{Cq}}$ method was used to analyze the relative change in gene expression. The primers (GAPDH, TNF- $\alpha$ and IL-6) were designed and synthesized by Sangon Biotech (Shanghai, China). The forward and reverse primers of target genes are listed in Additional file 1: Table S1 [29-31].

\section{Cell culture and treatment}

H9C2 rat embryo cardiomyocytes were purchased from the American Type Culture Collection (ATCC, Manassas, VA, USA) and cultured in Dulbecco' $s$ modified Eagle' s medium (DMEM) containing 10\% fetal bovine serum (Biowest S.A.S, Niayet, France) and 1\% penicillin/streptomycin (Gibco, Grand Island, NY) at $37{ }^{\circ} \mathrm{C}$, $5 \% \mathrm{CO}_{2}$. Cultured $\mathrm{H} 9 \mathrm{C} 2$ cells were treated with $\mathrm{rSj}$-Cys $(0.5 \mu \mathrm{g} / \mathrm{ml})$ for $0.5 \mathrm{~h}$, and then exposed to $1 \mu \mathrm{g} / \mathrm{ml}$ of LPS (Solaibao, Beijing, China) for $24 \mathrm{~h}$. Cells incubated with LPS without $\mathrm{rSj}$-Cys treatment, or cells incubated with $\mathrm{rSj}$-Cys or medium alone were used as controls. After $24 \mathrm{~h}$ of incubation, the culture was centrifuged at $1000 \times$ rpm for $15 \mathrm{~min}$ at $4{ }^{\circ} \mathrm{C}$, the supernatants were stored at $-80^{\circ} \mathrm{C}$ until use, and the cells were used for flow cytometry assays.

\section{Detection of myocardial cell apoptosis by flow cytometry (FCM)}

The LPS-induced myocardial cell apotosis was measured by annexin v-fitc and propidium iodide (pi) staining in accordance with the manufacturer's instructions (Invitrogen, Thermo Fisher Scientific). Flow cytometric analysis was performed on a CYTEK DxP AthenaTM Analyzer (CyTeK Biosciences, California, USA). The results were analyzed with FlowJo V7.6.5 software.

\section{Detection of MyD88 by western blotting}

MyD88 expression level in treated $\mathrm{H} 9 \mathrm{C} 2$ cells and myocardial tissue was determined by western blotting. Briefly, cells or left ventricular myocardium were collected and homogenized in ice-cold RIPA buffer containing $0.1 \%$ phenylmethylsulfonyl fluoride. The homogenates were centrifuged at $12,000 \times \mathrm{rpm}$ for $15 \mathrm{~min}$ at $4{ }^{\circ} \mathrm{C}$. Supernatants were collected and protein concentration was quantified using a BCA assay kit (Pierce, Rockford, IL, USA). Equal amounts of cell extracts or heart homogenates were separated by $12 \%$ SDS-PAGE and electroblotted onto PVDF membranes. After blocking with 5\% skimmed milk for $2 \mathrm{~h}$ at room temperature, membranes were incubated with rabbit anti-MyD88 antibody (1:800) (Cell Signaling Technology, Danvers, Massachusetts, USA) overnight at $4{ }^{\circ} \mathrm{C}$, followed by HRP-conjugated goat anti-rabbit IgG
(1:4000) (Merck Millipore, Basilica, Massachusetts, USA) for $1 \mathrm{~h}$ at $37^{\circ} \mathrm{C}$. Immunoreactive protein bands were visualized using a Tanon 5200 Chemiluminescence Imaging System (Tanon, Shanghai, China).

\section{Statistical analysis}

All data are expressed as the mean \pm standard error of the mean (SE), and statistical analyses were performed using GraphPad Prism 5.0 software (GraphPad Inc., La Jolla, CA, USA). One-way ANOVA followed by the Student-Newman-Keuls test was used for multigroup comparisons; $P$-value of $<0.05$ was considered statistically significant.

\section{Results}

Treatment with rSj-Cys alleviated sepsis-induced myocardial malfunction

Left ventricular function was examined by echocardiography $12 \mathrm{~h}$ after CLP surgery. As shown in Fig. 1a and c, CLP-induced sepsis caused a significant reduction of left ventricular systolic function in mice, characterized by reduced EF and FS compared with the sham operation group (ANOVA: $F_{(3,23)}=63.07, P<0.0001$ and $F_{(3,23)}=21.08, P<0.0001$, respectively). In contrast, $\mathrm{rSj}$-Cys treatment dramatically reversed the sepsisinduced decrease in the left ventricular EF and FS to a similar level in mice of the sham surgery control group (ANOVA: $F_{(3,23)}=63.07, P<0.0001$ and $F_{(3,23)}=21.08$, $P<0.0001$, respectively), indicating that treatment with $\mathrm{rSj}$-Cys reduced the sepsis-induced myocardial systolic malfunction in mice (Fig. 1c). In addition, administration of $\mathrm{rSj}$-Cys in sham surgery mice did not markedly alter left ventricular EF and FS compared with the sham group without treatment (Fig. 1c).

To assess the left ventricular diastolic function, the E/A ratio was calculated from Doppler-derived mitral valve inflow measurements. The results showed that sepsis mice displayed a significant decline in E/A ratio values compared to sham control mice (ANOVA: $F_{(3}$, ${ }_{23}=10.99, P<0.0002$ ) (Fig. 1b, d). Treatment with $\mathrm{rSj}$ Cys significantly recovered the E/A ratio to a similar level of mice which had received sham surgery or sham $+\mathrm{rSj}$-Cys (ANOVA: $F_{(3,23)}=10.99, P<0.0002$ ) (Fig. 1b, d). These results indicate that treatment with $\mathrm{rSj}$-Cys also improves sepsis-induced diastolic malfunction in mice. No significant difference was observed between the sham group and the sham $\mathrm{rSj}$-Cys-treated group in terms of E/A ratio (ANOVA: $F_{(3,23)}=10.99, P<0.0002$ ) (Fig. 1d). 
a

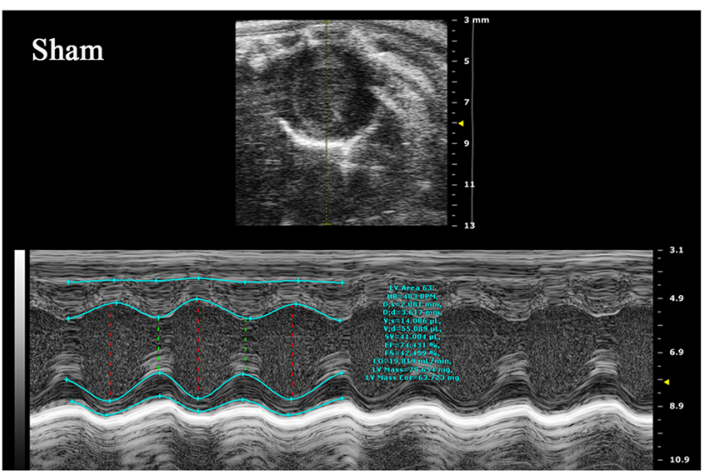

\section{CLP}
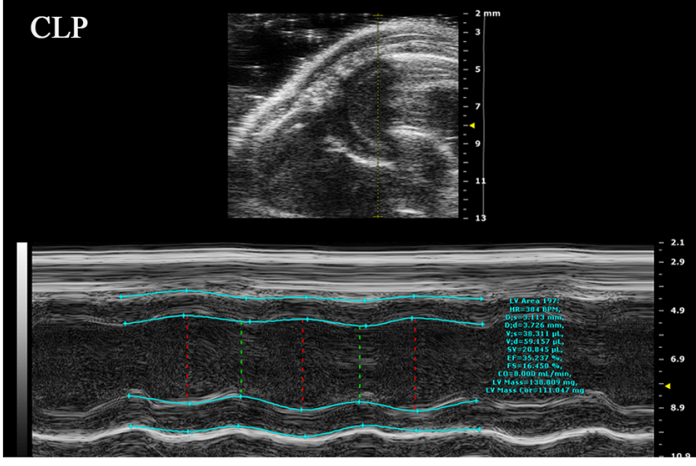

b
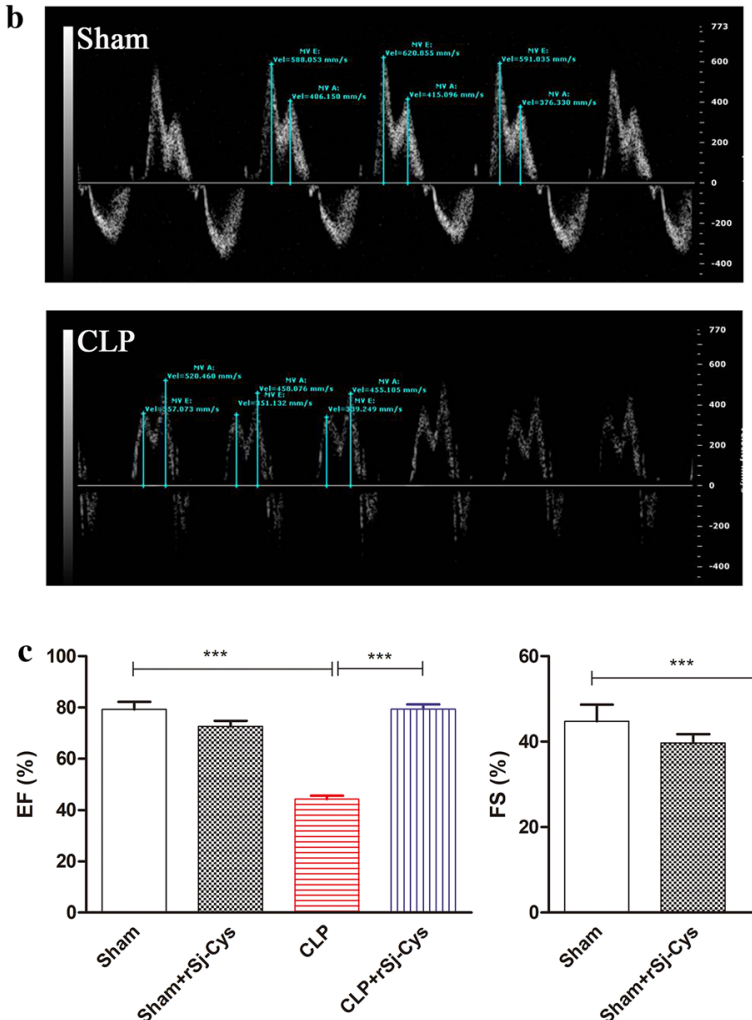
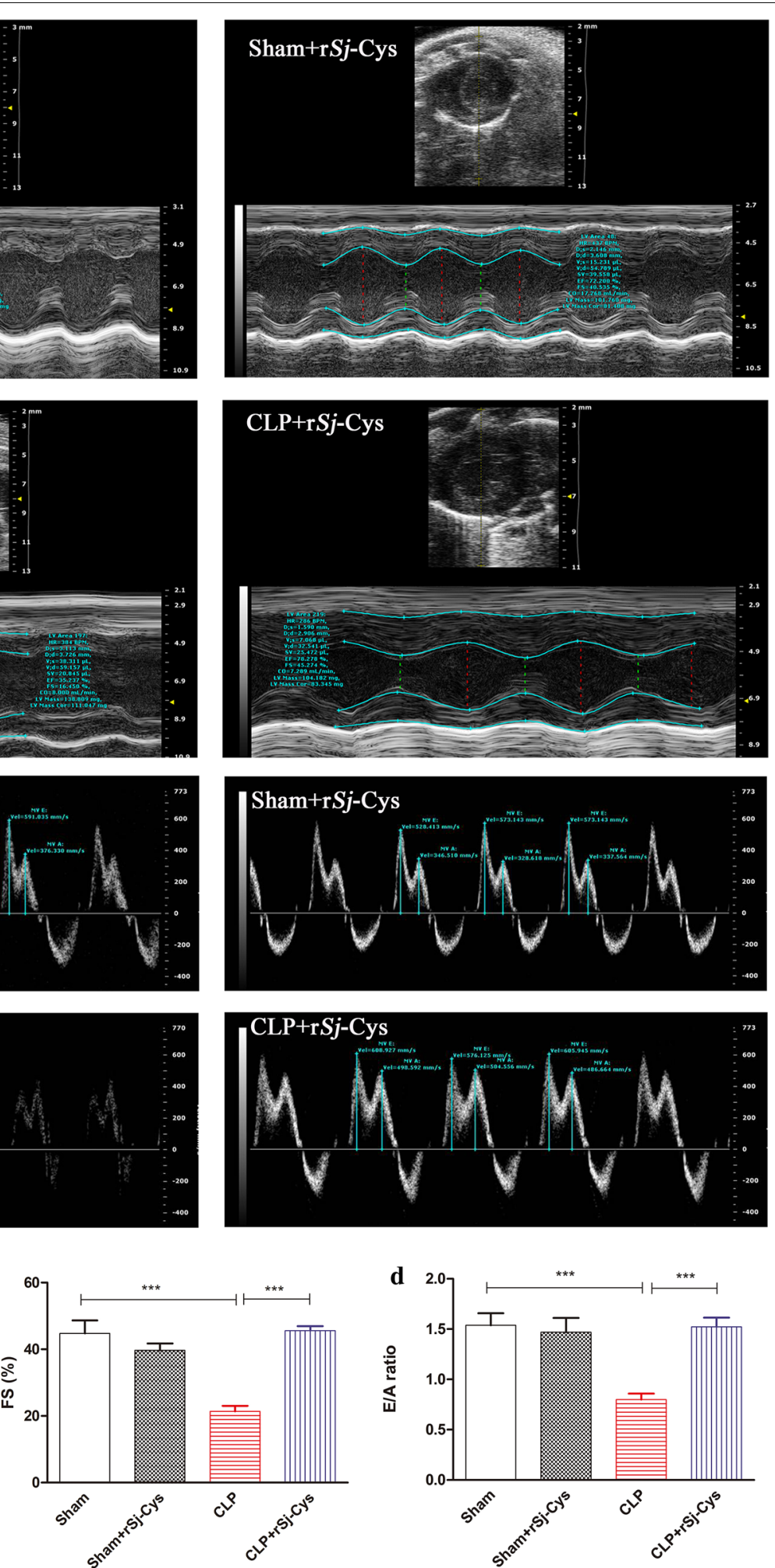

Fig. 1 Treatment of rSj-Cys improved the sepsis-induced myocardial malfunction. Representative M-mode echocardiograms obtained from mice $12 \mathrm{~h}$ after treatment of sham-operation, sham + rSj-Cys, CLP and CLP + rSj-Cys, respectively (a). The improved left ventricular systolic function evaluated by EF and FS after treatment with rSj-Cys (c). The improved CLP-induced left ventricular diastolic dysfunction was shown as representative transmitral Doppler images. The E wave represents peak early-diastolic transmitral velocity, and the A wave indicates peak late-diastolic transmitral velocity $(\mathbf{b})$. The changes of the E/A ratio were used to assess the alteration in left ventricular diastolic function (d). ( $n=6$ mice per group). Data are presented as the mean $\pm S E$. ${ }^{* * *} P<0.001$ 
Treatment of rSj-Cys reduced sepsis-induced pathological heart abnormalities

The morphological structures and pathology of the myocardial tissues of mice $12 \mathrm{~h}$ after CLP surgery were determined by H\&E staining. The results showed that the sham surgery group and sham with $\mathrm{rSj}$-Cys group had no significant inflammatory cell infiltration with normal appearance of the myofibrillar structure (Fig. 2a). However, the heart tissue in mice with CLP showed significant inflammation, myocardial fiber arrangement disorder and highly recruited inflammatory cell infiltration. Of note, tissue sections from the CLP $+\mathrm{rSj}$-Cys mice group showed significantly improved muscle fiber structure with reduced inflammatory cell infiltration compared with CLP group without rSj-Cys treatment (Fig. 2a). The pathological results indicate that $\mathrm{rSj}$-Cys effectively alleviates CLP-induced cardiac lesions and inflammation in mice.

\section{Administration of $\mathrm{rSj}$-Cys reduced sepsis-induced heart injury}

In myocardial injury, released $\mathrm{Mb}$, cTnI, NT-proBNP and MPO into sera or heart tissue are usually used as biomarkers to evaluate the ischemic severity of heart injury [32-34]. Compared with the sham group, the CLP group showed a marked increase in MPO activity in the myocardial tissue homogenate and elevated levels of cTnI, Mb, NT-proBNP in sera (ANOVA: $F_{(3}$, 23) $=32.10, \quad P<0.0001 ; \quad F_{(3,23)}=61.36, \quad P<0.0001 ; \quad F_{(3,}$, $\left.{ }_{23}\right)=10.42, \quad P<0.0002 ;$ and $F_{(3,23)}=42.79, \quad P<0.0001$, respectively) (Fig. 2b). After being treated with $\mathrm{rSj}$ Cys, the MPO activity in the myocardial homogenate and cTnI, Mb, NT-proBNP in sera were significantly reduced in mice with sepsis compared with CLP mice without treatment (ANOVA: $F_{(3,23)}=32.10, P<0.0001$; $F_{(3,23)}=61.36, P<0.0001 ; F_{(3,23)}=10.42, P<0.0002$; and $F_{(3,23)}=$ s42.79, $P<0.0001$, respectively) (Fig. $2 \mathrm{~b}$ ), while cTnI, NT-proBNP, Mb and MPO remained at low levels in mice with sham surgery and there was no significant difference between sham surgery groups and sham with treatment of $\mathrm{rSj}$-Cys groups. The increased MPO activity in the heart tissue of CLP-induced sepsis mice was correlated with the increased inflammatory cell infiltration, especially neutrophils, in the heart tissue (Fig. 2b).

\section{rSj-Cys inhibits pro-inflammatory cytokines and induces regulatory cytokines in mice with sepsis-caused heart injury}

To understand the mechanisms underlying the improvement of sepsis-caused cardiac dysfunction with treatment of $\mathrm{rSj}$-Cys, the levels of pro-inflammatory cytokines (TNF- $\alpha$ and IL-6) and regulatory cytokines (IL-10 and
TGF- $\beta$ ) were measured in sera, and the mRNA levels measured in heart tissue of experimental mice. The results showed that the inflammatory cytokines (TNF- $\alpha$ and IL-6) dramatically increased in the sera of CLPinduced sepsis mice, compared to that in mice with sham surgery only or sham + rSj-Cys (ANOVA: $F_{(3,23)}=18.39$, $P<0.0001$ and $F_{(3,23)}=361.3, P<0.0001$, respectively) (Fig. 3a). Treatment with rSj-Cys significantly reduced the production of TNF- $\alpha$ and IL- 6 in CLP-induced sepsis mice, compared with CLP mice without treatment (ANOVA: $F_{(3,23)}=18.39, P<0.0001$ and $F_{(3,23)}=361.3$, $P<0.0001$, respectively) (Fig. 3a). However, there was no significant difference of TNF- $\alpha$ and IL- 6 levels in sera of mice between the sham group and sham $+\mathrm{rSj}$ Cys group (ANOVA: $F_{(3,23)}=18.39, P<0.0001$ and $F_{(3}$, 23) $=361.3, P<0.0001$, respectively) (Fig. 3a). The reduced TNF- $\alpha$ and IL- 6 levels were correlated with the increased IL-10 and TGF- $\beta$ levels in sera of CLP-induced sepsis mice treated with $\mathrm{rSj}$-Cys compared with the CLP group without treatment (Fig. 3a). The IL-10 and TGF- $\beta$ levels were significantly lower in CLP-induced sepsis mice than that in sham surgery or sham $+\mathrm{rSj}$-Cys mice (ANOVA: $F_{(3,23)}=9.032, P<0.0006$ and $F_{(3,23)}=9.789, P<0.0004$, respectively) (Fig. 3a). The mRNA expression levels of pro-inflammatory cytokines (TNF- $\alpha$ and IL-6) and regulatory cytokines (IL-10 and TGF- $\beta$ ) detected in heart tissue showed a similar pattern to that measured in sera (Fig. 3b). The results suggested that CLP-induced sepsis mice stimulated the secretion of pro-inflammatory cytokines (TNF- $\alpha$ and IL-6), but inhibited the regulatory immune pathway (lower levels of IL-10 and TGF- $\beta$ ). Treatment of rSj-Cys was able to significantly inhibit the activation of the pro-inflammatory pathway, possibly by activating the regulatory immune pathway. Interestingly, the mRNA level of the M1 macrophage marker iNOS was significantly reduced, and the M2 macrophage maker Arg-1 significantly increased in heart tissues of $\mathrm{rSj}$-Cystreated sepsis-mice (ANOVA: $F_{(3,11)}=4.967, P<0.0311$ and $F_{(3,11)}=77.27, P<0.0001$, respectively) (Fig. $3 \mathrm{~b}$ ), indicating that more macrophages shifted from M1 to M2 after being treated with $\mathrm{rSj}$-Cys.

\section{The inhibitory effect of rSj-Cys on LPS-induced inflammatory response in $\mathrm{H} 9 \mathrm{C} 2$ cardiomyocytes}

LPS is thought to be the major component to cause cardiac dysfunction in sepsis by inducing the innate immune inflammatory response [35]. In the present study, we identified that LPS significantly induced H9C2 cardiomyocytes to release pro-inflammatory cytokines IL-6 and TNF $-\alpha$ (ANOVA: $F_{(3,11)}=20.78, P<0.0004$ and $F_{(3,11)}=18.53, P<<0.0006$, respectively), but inhibited the release of regulatory cytokines TGF- $\beta$ and IL-10 (ANOVA: $F_{(3,11)}=25.67, P<0.0002$ and $F_{(3,11)}=14.41$, 
$P<0.0014$, respectively) compared with cells treated with PBS (Fig. 4a). After being treated with $\mathrm{rSj}$-Cys, the LPSinduced IL- 6 and TNF- $\alpha$ were reduced to the level of cells unstimulated by LPS (ANOVA: $F_{(3,11)}=20.78, P<0.0004$ and $F_{(3,11)}=18.53, P<0.0006$, respectively), and TGF- $\beta$ and IL-10 were significantly boosted compared to cells without $\mathrm{rSj}$-Cys treatment (ANOVA: $F_{(3,11)}=25.67$, $P<0.0002$ and $F_{(3,11)}=14.41, P<0.0014$, respectively) (Fig. 4a). The rSj-Cys alone had no significant effect on the innate immune response of normal cardiomyocytes.

\section{rSj-Cys reduced LPS-induced cardiomyocyte apoptosis}

To further determine whether $\mathrm{rSj}$-Cys reduced LPSinduced cardiomyocyte apoptosis, H9C2 cells were incubated with LPS alone or with rSj-Cys. The flow cytometry results revealed that incubation with LPS induced apoptosis in $14.4 \%$ of $\mathrm{H} 9 \mathrm{C} 2$ cells, whereas co-incubation with $\mathrm{rSj}$-Cys significantly reduced LPS-induced apoptosis to a level similar to cells without LPS (ANOVA: $F_{(3,}$ ${ }_{11)}=22.68, P<0.0003$ ) (Fig. 4b). There was no significant difference in the apoptotic rate between the rSj-Cysalone group and blank control group.

\section{rSj-Cys suppressed the activation of MyD88 in LPS-stimulated $\mathrm{H} 9 \mathrm{C} 2$ cells in vitro and CLP-induced cardiac tissues in vivo}

MyD88 is a crucial molecule involved in the inflammatory TLR signaling pathway. To determine if MyD88 is involved in the therapeutic effect of $\mathrm{rSj}$-Cys on sepsisinduced inflammation and damage of cardiomyocytes, we detected the expression of MyD88 in heart tissue of mice with CLP-induced sepsis treated with $\mathrm{rSj}$-Cys in vivo, and in LPS-stimulated $\mathrm{H} 9 \mathrm{C} 2$ cells co-incubated with $\mathrm{rSj}$-Cys in vitro. The elevated level of MyD88 was observed in cardiac tissue $12 \mathrm{~h}$ after CLP surgery compared with the sham surgery control (ANOVA: $F_{(3,11)}=8.823, P<0.0064$ ) (Fig. 4c). Treatment with $\mathrm{rSj}$-Cys significantly reduced the expression of MyD88 in cardiac tissue of sepsis mice compared with mice without treatment (ANOVA: $F_{(3}$, 11) $=8.823, P<0.0064$ ) (Fig. 4c). There was no effect of $\mathrm{rSj}$ Cys on the expression of MyD88 in normal mice (sham control). Meanwhile, the expression of MyD88 was also increased in cardiomyocytes incubated with LPS for $24 \mathrm{~h}$. Co-incubation with rSj-Cys significantly suppressed the expression of MyD88 in LPS-stimulated cardiomyocytes (ANOVA: $F_{(3,11)}=8.550, P<0.0071$ ) (Fig. 4 d).

\section{Discussion}

Myocardial dysfunction is a fatal complication of patients with sepsis [18]. Studies have found that $50 \%$ of patients with sepsis have systolic and diastolic dysfunction in the heart left and right ventricle, possibly caused by endotoxin-induced myocardial injury [36] which has been confirmed both in animal and clinical observations [37]. In this study, we also confirm that CLP-induced sepsis caused serious myocardial damage characterized by a significant reduction of left ventricular systolic and diastolic functions in mice, which closely mimicked the pathological features of myocardial infarction observed in clinical patients [38]. We further confirm that LPS released by Gram-negative bacteria could cause apoptosis of $\mathrm{H} 9 \mathrm{C} 2$ cardiomyocytes when co-incubated in vitro.

Cysteine proteases have been regarded as key molecules in regulating inflammation, cell apoptosis, cancer progression, protein degradation and antigen presentation [39-43]. Since cysteine proteases are largely involved in the inflammation and immune responses, their inhibitor, cystatin, could be a potential modulator for an immunological reaction. Actually, the cystatins secreted by several helminths have been proven to play important roles in modulating host immune responses [11, 21]. Previous studies demonstrated that S. japonicum cystatin (Sj-Cys) contained conserved domains of type II family cystatins with inhibitory activity on bovine cathepsin B [23]. Sj-Cys also inhibited LPS-stimulated macrophages to release nitric oxide, TNF- $\alpha$ and IL- 6 cytokines and induced M2 macrophage polarization [23]. Treatment with $\mathrm{rSj}$-Cys significantly reduced TNBS-induced experimental colitis in mice through upregulation of Treg cells and related cytokines IL-10 and TGF- $\beta$, and downregulation of proinflammatory cytokines TNF- $\alpha$ and IL- 6 in the colon tissues of mice [44].

In an effort to reduce sepsis-induced cardiomyopathy, the life-threatening complication and consequence of systemic infection, we established the mouse model of CLP-induced sepsis and sepsis-induced cardiomyopathy. We demonstrated that $12 \mathrm{~h}$ after CLP, the ventricular systolic and diastolic functions of affected mouse heart were seriously impaired associated with myocardial structural damage and inflammatory cell infiltration. Physiological changes in cardiac dysfunction include ventricular dilatation, decreased ejection fraction, systemic or regional left ventricular wall

\footnotetext{
(See figure on next page.)

Fig. 2 a Histopathological and morphological variations in the cardiac tissue of mice following sham surgery, sham + rSj-Cys, CLP and CLP + rSj-Cys ( $n=6$ mice per group, 200x magnification). Treatment with rSj-Cys reduced CLP-sepsis induced myocardial injury in the BALB/c mice. $\mathbf{b}$ The levels of CTnl, NT-proBNP, Mb in sera and MPO activity in heart tissue were significantly reduced in CLP mice treated with rSj-Cys. The data are presented as the mean \pm SE. ${ }^{* *} P<0.01,{ }^{* * *} P<0.001$. Scale-bars: $50 \mu \mathrm{m}$
} 


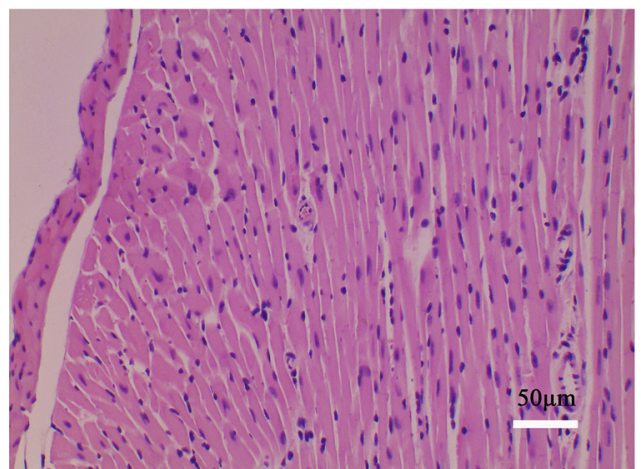

Sham

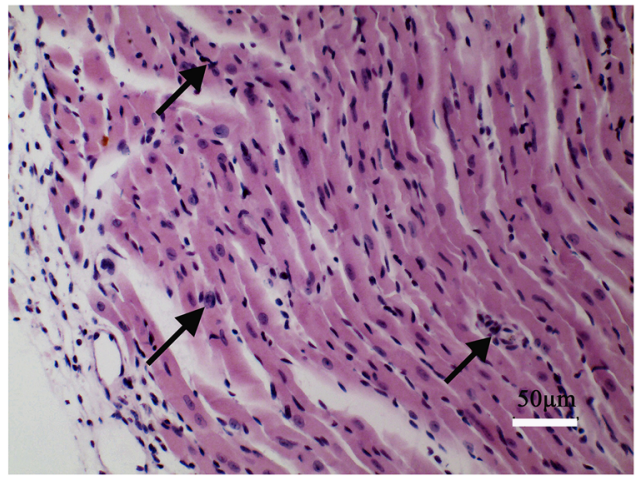

CLP

b
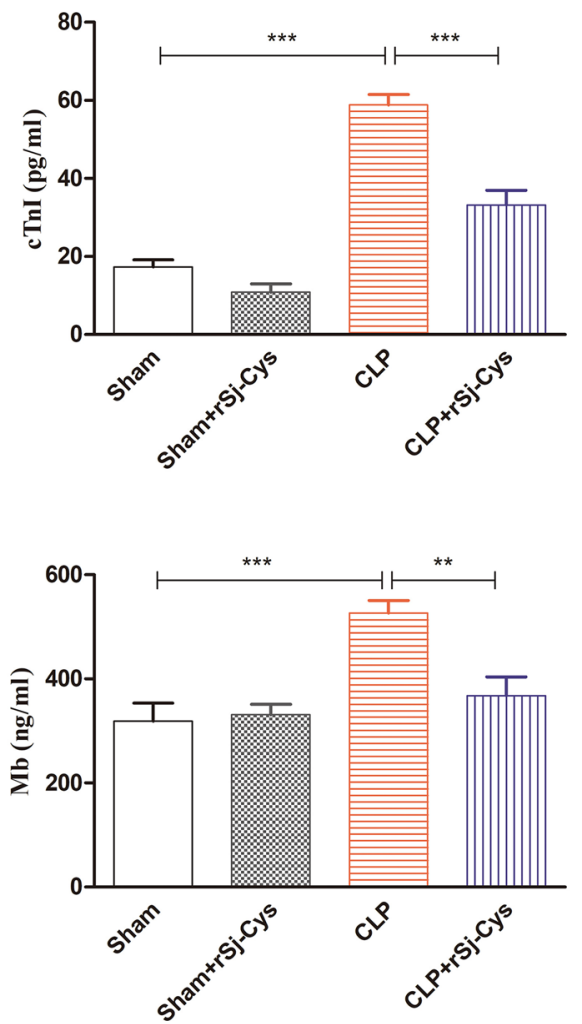

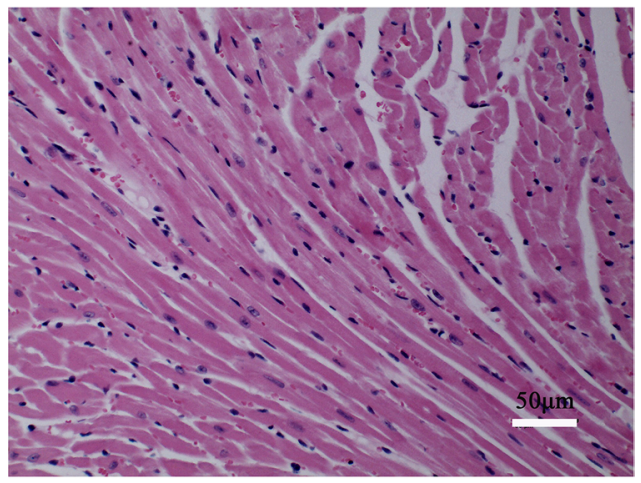

Sham $+\mathrm{rSj}$-Cys

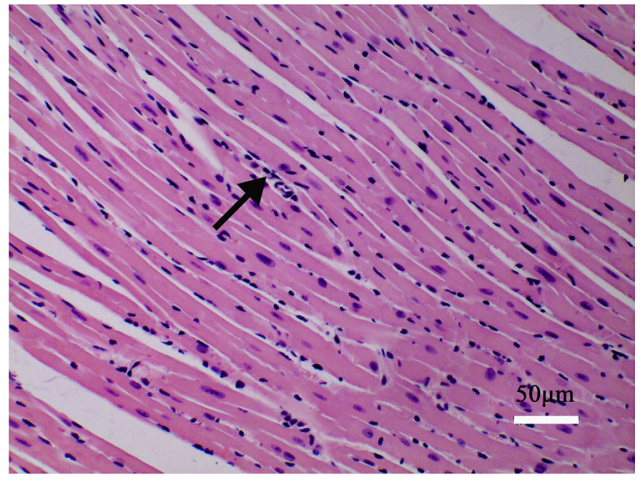

$\mathrm{CLP}+\mathrm{rSj}$-Cys
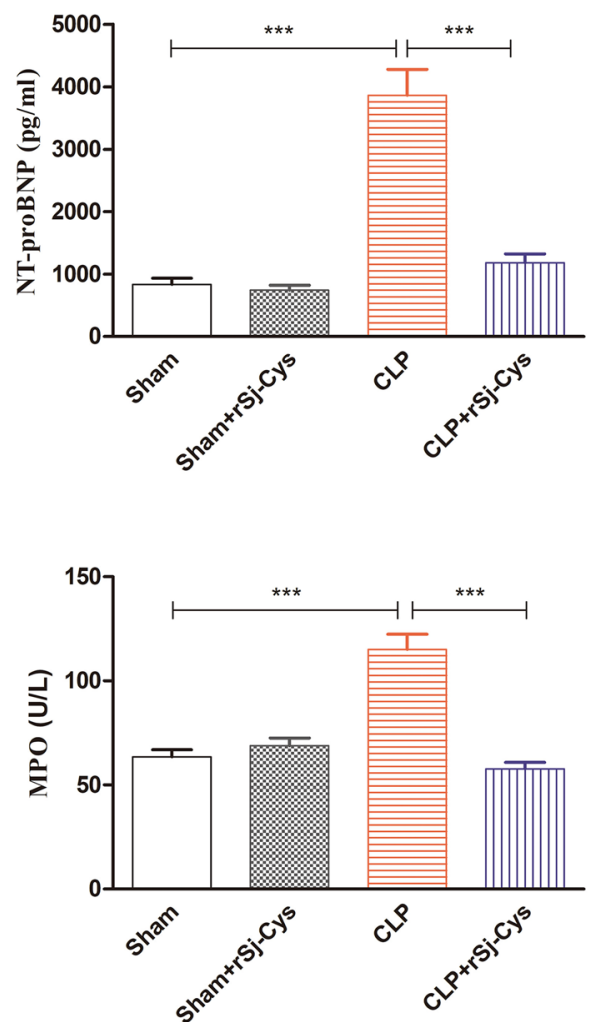
dysfunction and systolic and diastolic dysfunction [45]. EF\%, FS\% and the E/A ratio of the left ventricle (LV) are important indicators reflecting cardiac function [46, 47]. Echocardiographic results demonstrated that the CLP-induced sepsis resulted in a significant decrease in left ventricular EF, FS and E/A ratio, indicating the serious damage on heart systolic and diastolic functions. In addition, the levels of cTnI, NTproBNP and Mb in sera and the MPO level in heart tissue are the important biochemical markers of cardiac damage and injury in early septic shock [32, 33, 48, 49]. The CLP-induced sepsis model established in this study demonstrated significantly increased levels of cTnI, NT-proBNP and Mb in sera and a high level of MPO in heart tissue, indicating that the heart tissue and cells were seriously damaged as a result of the CLP-induced sepsis. The significantly increased inflammatory cell infiltration in heart tissue also demonstrated the serious inflammation occurring in the heart.

After being treated with $\mathrm{rSj}$-Cys, the sepsis-induced heart malfunction has been significantly improved, showing a recovered left ventricular EF, FS and E/A ratio. The inflammation of heart tissue was also significantly reduced, as illustrated by the significantly decreased infiltration of inflammatory cells in cardiac tissues and fiber swelling. The levels of Mb, cTnI and NT-proBNP in sera were significantly reduced upon the treatment, indicating that $\mathrm{rSj}$-Cys attenuated endotoxin-induced myocardial damage and dysfunction. The MPO level was also reduced in heart tissue. Neutrophils play a significant role in the development of inflammation [50], and the activated neutrophils and monocytes are the main sources of MPO [51]. MPO is released into the blood as an inflammatory mediator, and promotes the activation of neutrophils, leading to further increased MPO and inflammation. Studies have also shown that neutrophil recruitment mediated myocardial injury and cardiac dysfunction induced by ischemia-reperfusion [52]. After treatment with $\mathrm{rSj}$-Cys, the levels of these biochemical markers of cardiac injury were significantly reduced, which was associated with the reduction of inflammatory cell infiltration in the heart and the proinflammatory cytokines (IL- 6 and TNF- $\alpha$ ) in sepsis mice.

Pro-inflammatory cytokines IL-6 and TNF- $\alpha$ play essential roles in the onset and progression of sepsis [53], and their over-expression was seen as an early signal suppressing myocardial contraction and the major cause of progressive systolic dysfunction [36, 54]. As a triggering factor of inflammation, TNF- $\alpha$ is also recognized as a main mediator of septic shock, and involved in the induction of IL-1 production, the latter induces the secretion of secondary inflammatory factors such as IL-6, resulting in an inflammatory cascade [55-57]. Further evidence has suggested that overexpressed IL- 6 and TNF- $\alpha$ by systematic immune responses might support a vital role in the development of myocardial malfunction in sepsis [58]. At the same time, the septic cardiomyocytes were able to produce TNF- $\alpha$ and IL- 6 themselves, indirectly leading to deteriorative damage to myocardial tissues [3]. The present study showed that treatment with $\mathrm{rSj}$ Cys significantly reduced the level of TNF- $\alpha$ and IL- 6 in sera (systematic) and their mRNAs in cardiac homogenate (local), suggesting the regulatory effects of $\mathrm{rSj}$-Cys on local (cardiac) and systematic (sepsis) immune system.

Further evidence has shown that immunomodulatory functions of helminth infection or helminth-derived products are mediated by stimulating the host regulatory $\mathrm{T}$ cell (Treg) response $[16,17,20]$. Tregs are key factors in the induction of immune tolerance [59], mainly through the secretion of IL-10 and TGF- $\beta$ to exert regulatory influence on the immune system [16]. IL-10 played a counter-regulatory effect in the inflammatory response and was an endogenous inhibitor of inflammatory cytokine production [60]. The levels of IL-10 and TGF- $\beta$ were dramatically increased upon the treatment of $\mathrm{rSj}$-Cys in this study, indicating that $\mathrm{rSj}$-Cys acted as an inhibitory immunomodulator in the case of excessive inflammation infection possibly through stimulating Treg and Treg cell-secreted IL-10 and TGF- $\beta$. The $\mathrm{rSj-Cys}$ itself had little effect on the cytokines change compared to the control mice without $\mathrm{rSj}$-Cys treatment, suggesting that $\mathrm{rSj}$-Cys mainly plays a immunomodulatory role when inflammation is activated. Incubation of $\mathrm{rSj}$-Cys with $\mathrm{H} 9 \mathrm{C} 2$ cardiomyocytes in vitro inhibited LPS-induced heart cell apoptosis and induced similar cytokine changes in the culture supernatant to that in septic cardiomyopathy in vivo, further indicating that LPS-induced hyper-inflammatory responses resulted in cardiomyocyte apoptosis, and treatment with $\mathrm{rSj}$-Cys could inhibit LPS-triggered excessive inflammation partially through directly inhibiting the inflammatory cytokine IL- 6 and TNF- $\alpha$ and stimulating the regulatory cytokines IL-10 and TGF- $\beta$ in LPS-shocked cardiomyocytes. The reduced inflammatory cytokines may relatively contribute to the decline in myocardial apoptosis.

Another interesting finding in this study is that heart tissue from $\mathrm{rSj}$-Cys-treated sepsis-mice expressed more Arg-1 and less iNOS compared to the mice without $\mathrm{rSj}$-Cys treatment. Arg-1 is the biomarker for M2 alternatively activated macrophages that release antiinflammatory cytokines to suppress immune responses and restore tissue homeostasis whereas iNOS is the biomarker of M1 classically activated macrophages responsible for the pro-inflammatory response. The shifting of 

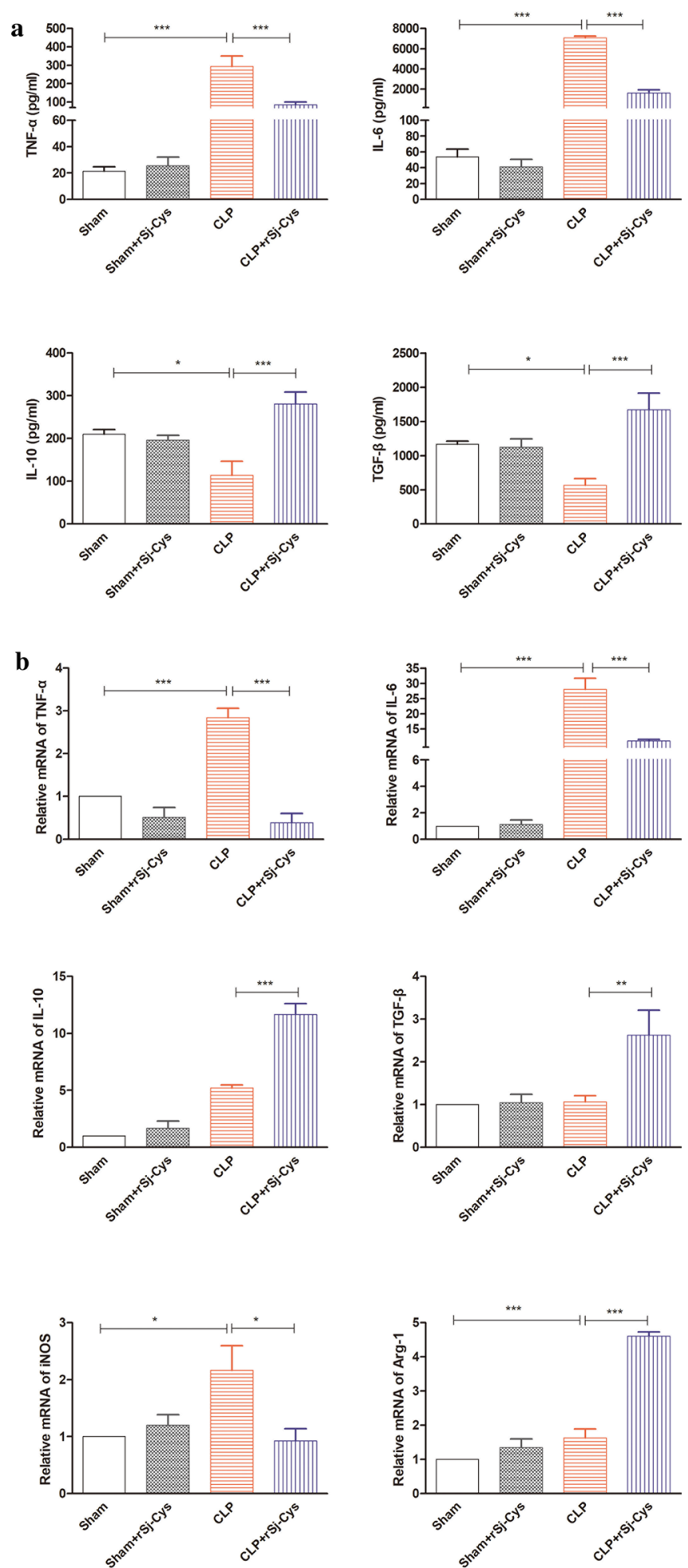

Fig. 3 Treatment with rSj-Cys reduced the pro-inflammatory cytokine (TNF-a and IL-6) and boosted regulatory cytokine (IL-10 and TGF- $\beta$ ) levels in sera $(\mathbf{a})$ and the similar mRNA expression pattern observed in heart tissues $(\mathbf{b})$ of mice with CLP-induced sepsis $12 \mathrm{~h}$ after treatment. The mRNA expression level of M1 macrophage marker (iNOS) was reduced and that of M2 macrophage marker (Arg-1) increased in heart tissues (b). The data are shown as the mean $\pm \mathrm{SE}$ for each group $\left(n=3\right.$ mice per group). ${ }^{*} P<0.05,{ }^{* *} P<0.01,{ }^{* * *} P<0.001$ 
Fig. 4 a Incubation with rSj-Cys inhibited the pro-inflammatory cytokines TNF- $a$ and IL- 6 and stimulated regulatory cytokines IL-10 and TGF- $\beta$ released by LPS-induced $\mathrm{H} 9 \mathrm{C} 2$ cells. The levels of these cytokines in the supernatant were measured by ELISA $24 \mathrm{~h}$ after incubation. The results are shown as the mean \pm SE for each group ( $n=3$ per group). b rSj-Cys reduced LPS-induced cardiomyocyte apoptosis measured by flow cytometry. Representative flow cytometry images showed the reduced cardiomyocyte apoptosis in rSj-Cys + LPS co-incubated H9C2 cells. The normal H9C2 cells in blank medium or medium with rSj-Cys were used as controls. Data are expressed as mean \pm SE from three independent experiments) ( $n=3$ per group). rSj-Cys treatment suppressed the expression of MyD88 in the myocardial tissues of mice with CLP-induced sepsis (c) $(n=6$ mice per group) and in LPS-incubated H9C2 cells (d) $(n=3$ per group) measured by western blot. $\beta$-actin was measured as a control. The density ratio of MyD88/ $\beta$-actin is shown on the right. The results are shown as the density mean \pm SE for each group. ${ }^{*} P<0.05$, ${ }^{*} P<0.01,{ }^{* *} P<0.001$

pro-inflammatory M1 macrophages to anti-inflammatory M2 macrophages in the heart tissue of sepsis mice after being treated with $\mathrm{rSj}$-Cys may provide another mechanism involved in the reduced inflammation and heart damage caused by sepsis. M2-type macrophages have been reported to attenuate experimental inflammation in dinitrobenzene sulfonic acid (DNBS)-induced colitis in mice $[61,62]$.

LPS associates with its receptor, the toll-like receptor 4 (TLR4), through the help of LPS-binding protein CD14, subsequently resulting in the production of inflammatory cytokines, such as TNF- $\alpha$, IL-1 $\beta$ and IL-18, which might directly harm cardiac function [63]. Although the mechanism leading to sepsis-induced cardiac arrest remains controversial, there is increasing evidence supporting that TLR-mediated innate immunity and inflammatory responses play a key role in cardiac dysfunction caused by sepsis or septic shock [64-66]. Activation of the TLR4 signaling pathway may directly lead to myocardial cells' dysfunction. The invaded bacteria or other external stimulus first trigger innate immunity and then induce TLR4 expression by upregulating the MyD88-mediated pathway and activating the transcription of nuclear factor- $\mathrm{k} B$ $(\mathrm{NF}-\mathrm{kB})$, resulting in the production of various inflammatory mediators, such as cytokines, chemokines and antimicrobial peptides [67]. The occurrence of sepsis is related to the TLR4/MyD88 signaling pathway, which activates the secretion of cytokines associated with cardiac dysfunction in adult mammalian heart $[7,68]$ and in mice [69]. To investigate whether $\mathrm{rSj}$-Cys-involved antiinflammatory and anti-apoptosis effects through inhibiting the MyD88-dependent signaling pathway, the level of MyD88 in CLP-induced septic heart tissue and in LPSstimulated $\mathrm{H} 9 \mathrm{C} 2$ cells was measured. Our study found that the expression of MyD88 increased in CLP-induced
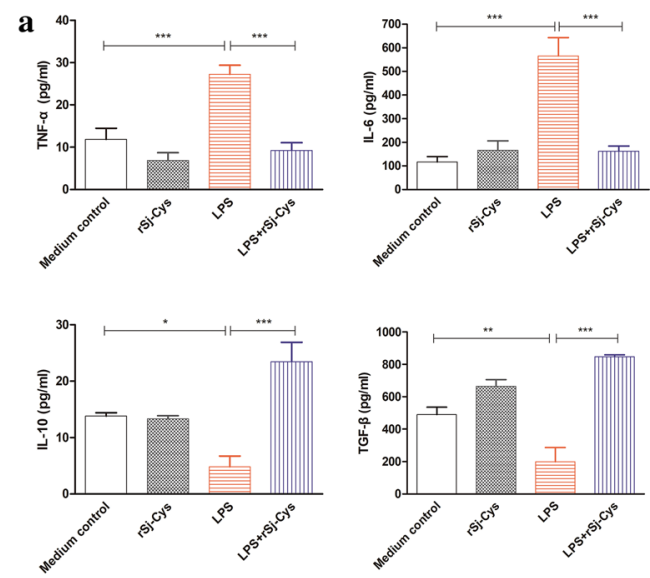

b
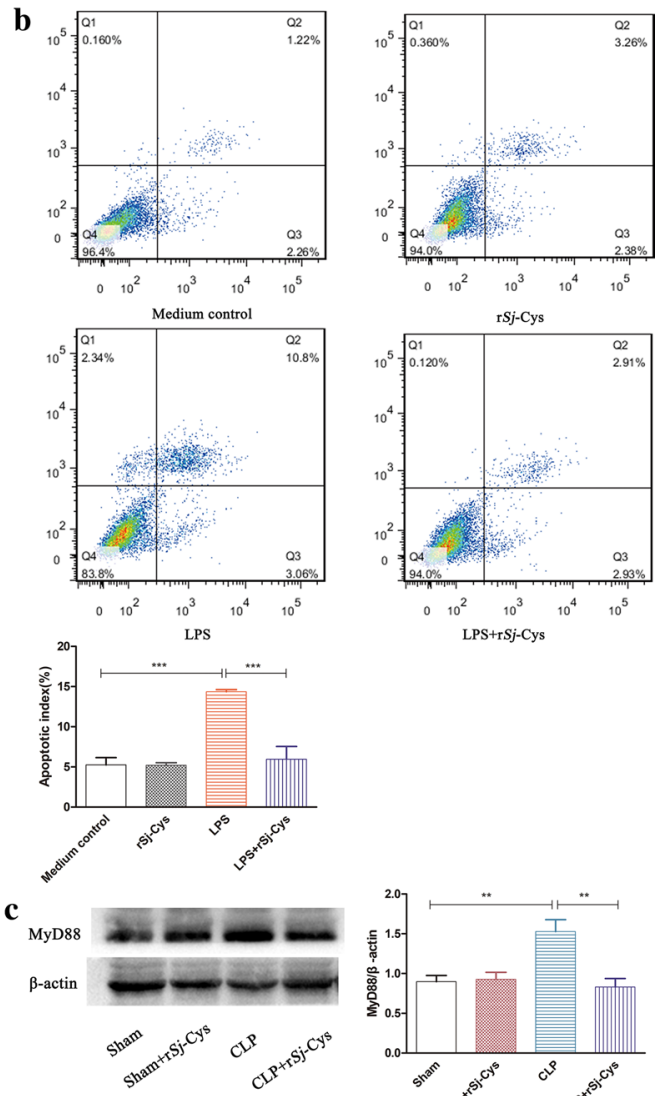

d
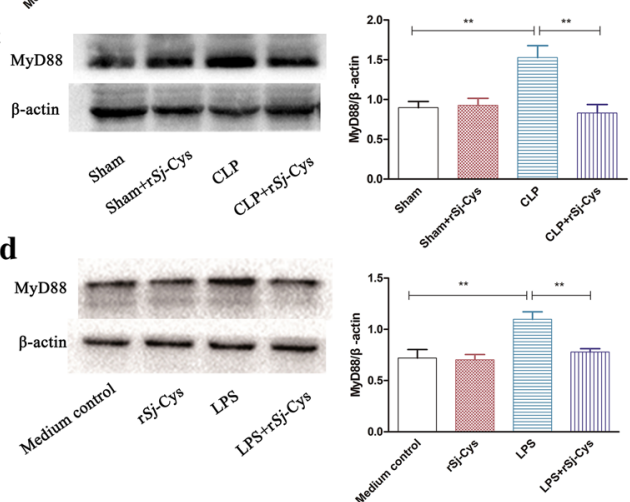

myocardial tissue or LPS-stimulated $\mathrm{H} 9 \mathrm{C} 2$ cells, and treatment with $\mathrm{rSj}$-Cys significantly reduced the expression of MyD88 in these cardiomycytes. It is under investigation whether treatment of $\mathrm{rSj}$-Cys reduces TLR-2 
or TLR-4 activation that results in downregulation of MyD88.

Our results suggest the possible mechanism of $\mathrm{rSj}$-Cys involved in the alleviation of septic cardiomyopathy is that treatment of $\mathrm{rSj}$-Cys stimulates Tregs and/or cardiomyocytes to produce regulatory cytokines such as IL-10 and TGF- $\beta$, and promotes the differentiation of M1 to M2 macrophages in heart tissue, thereby suppressing the production of pro-inflammatory cytokines via inhibiting the MyD88 activation signal pathway as shown for other helminth-derived proteins [70-73].

\section{Conclusions}

The present data show that $\mathrm{rSj}$-Cys strongly alleviated excessive inflammation and protected against sepsisinduced cardiac dysfunction. Therefore, rSj-Cys could be considered as a potential therapeutic agent for the prevention and treatment of sepsis associated cardiac dysfunction.

\section{Supplementary information}

Supplementary information accompanies this paper at https://doi. org/10.1186/s13071-020-04104-3.

Additional file 1: Table S1. Primer sequences used for QRT-PCR analysis.

\begin{abstract}
Abbreviations
CLP: cecal ligation and puncture; LPS: lipopolysaccharides; Mb: myoglobin; cTnl: cardiac troponin l; NT-proBNP: N-terminal pro-Brain Natriuretic peptide; MPO: myeloperoxidase; MyD88: myeloid differentiation factor 88; EF: ejection fraction; FS: fractional shortening; E wave: peak early-diastolic transmitral velocities; A wave: peak late-diastolic transmitral velocities; LV: left ventricle; ELISA: enzyme-linked immunosorbent assay; TNF-a: tumor necrosis factor alpha; IL-6: interleukin 6; IL-10: interleukin 10; TGF- $\beta$ : transforming growth factor- $\beta$; IL-1 $\beta$ : interleukin $1 \beta$; DCs: dendritic cells; Tregs: regulatory T cells; DNBS: dinitrobenzene sulfonic acid; DSS: dextran sulfate sodium; TLR4: tolllike receptor 4; NF-kB: nuclear factor-KB; SE: standard error of the mean; SPF: specific pathogen free; SDS-PAGE: sodium dodecyl sulfate polyacrylamide gel electrophoresis; PVDF: polyvinylidene fluoride.
\end{abstract}

\section{Acknowledgments}

We thank Dr Li He at the Basic Medical School of Wuhan University, for providing the recombinant plasmid. We thank Dr Qin Gao at the Basic Medical College of Bengbu Medical College, for providing H9C2 cells.

\section{Authors' contributions}

$X Y, H C$ and SG conceived and designed the study. SG, HL, HX, SS, HY, LW, YB, QZ and XW performed the experiments. YY, SW and LC analyzed the data. SG wrote the manuscript. BZ, XY and $\mathrm{HC}$ critically revised the manuscript. All authors read and approved the final manuscript.

\section{Funding}

This project was supported by the Scientific Research Innovation Platform Team of University (No. 2016-40), the Cardiovascular Injury and Protection Foundation and Clinical Application Innovation Team (No. BYKC201906), the Science Foundation of Anhui Province (No. gxbjZD15, 201904a07020017 and $2018 \mathrm{H} 174$ ), the Program of Natural Science Foundation of the Anhui Higher Education Institutions (No. KJ2019A0383), the Science Foundation of Bengbu Medical College (No. BYTM2019002), the Postgraduate Scientific Research Innovation Program of Bengbu Medical College (No. Byycx1828,
Byycx1920 and Byycx1903) and the National University Students' Innovation and Entrepreneurship Training Program (No. 201910367025, 201810367012 and 201910367002)

\section{Availability of data and materials}

The datasets supporting the findings of this article are included within the article and its additional file.

\section{Ethics approval and consent to participate}

All procedures concerning laboratory animals were in strict accordance with the Chinese National Institute of Health Guide for the Care and Use of Laboratory Animals, and approved by the Animal Care and Use Committee of Anhui Medical University (approval no. AMU26-08061).

\section{Consent for publication}

Not applicable.

\section{Competing interests}

The authors declare that they have no competing interests.

\section{Author details}

1 Second Affiliated Hospital of Bengbu Medical College, Bengbu 233000, China. ${ }^{2}$ Anhui Key Laboratory of Infection and Immunity of Bengbu Medical College, Bengbu 233000, China. ${ }^{3}$ Basic Medical College of Bengbu Medical College, Bengbu 233000, China. ${ }^{4}$ First Affiliated Hospital of Bengbu Medical College, Bengbu 233000, China. ${ }^{5}$ National School of Tropical Medicine, Baylor College of Medicine, Houston, TX 77030, USA.

Received: 22 December 2019 Accepted: 27 April 2020

Published online: 18 May 2020

\section{References}

1. Fleischmann C, Scherag A, Adhikari NK, Hartog CS, Tsaganos T, Schlattmann P, et al. Assessment of global incidence and mortality of hospitaltreated sepsis. Am J Respir Crit Care Med. 2016;193:259-72.

2. Becker JU, Theodosis C, Jacob ST, Wira CR, Groce NE. Surviving sepsis in low-income and middle-income countries: new directions for care and research. Lancet Infect Dis. 2009;9:577-82.

3. Buerke U, Carter JM, Schlitt A, Russ M, Schmidt H, Sibelius U, et al. Apoptosis contributes to septic cardiomyopathy and is improved by simvastatin therapy. Shock. 2008;29:497-503.

4. Rudiger A, Singer M. Mechanisms of sepsis-induced cardiac dysfunction. Crit Care Med. 2007;35:1599-608.

5. Wang Y, Zhang H, Chai F, Liu X, Berk M. The effects of escitalopram on myocardial apoptosis and the expression of Bax and $\mathrm{BCl}-2$ during myocardial ischemia/reperfusion in a model of rats with depression. BMC Psychiatry. 2014;14:349.

6. Merx MW, Weber C. Sepsis and the heart. Circulation. 2007;116:793-802.

7. Feng Y, Zou L, Chen C, Li D, Chao W. Role of cardiac- and myeloid-MyD88 signaling in endotoxin shock: a study with tissue-specific deletion models. Anesthesiology. 2014;121:1258-69.

8. Elliott DE, Weinstock JV. Helminth-host immunological interactions: prevention and control of immune-mediated diseases. Ann NY Acad Sci. 2012;1247:83-96.

9. Babu S, Kumaraswami V, Nutman TB. Alternatively activated and immunoregulatory monocytes in human filarial infections. J Infect Dis. 2009;199:1827-37.

10. O'Regan NL, Steinfelder S, Venugopal G, Rao GB, Lucius R, Srikantam A, et al. Brugia malayi microfilariae induce a regulatory monocyte/ macrophage phenotype that suppresses innate and adaptive immune responses. PLoS Negl Trop Dis. 2014;8:e3206.

11. Passos LS, Gazzinelli-Guimaraes PH, Oliveira Mendes TA, Guimaraes AC, Silveira Lemos DD, Ricci ND, et al. Regulatory monocytes in helminth infections: insights from the modulation during human hookworm infection. BMC Infect Dis. 2017;17:253.

12. Li H, Wang S, Zhan B, He W, Chu L, Qiu D, et al. Therapeutic effect of Schistosoma japonicum cystatin on bacterial sepsis in mice. Parasit Vectors. 2017;10:222. 
13. Anthony RM, Urban JF Jr, Alem F, Hamed HA, Rozo CT, Boucher JL, et al. Memory $T(H) 2$ cells induce alternatively activated macrophages to mediate protection against nematode parasites. Nat Med. 2006;12:955-60.

14. Bisht N, Khatri V, Chauhan N, Kalyanasundaram R. Cystatin from filarial parasites suppress the clinical symptoms and pathology of experimentally induced colitis in mice by inducing T-regulatory cells, B1-cells, and alternatively activated macrophages. Biomedicines. 2019;7:85.

15. Hubner MP, Layland LE, Hoerauf A. Helminths and their implication in sepsis - a new branch of their immunomodulatory behaviour? Pathog Dis. 2013;69:127-41.

16. Hewitson JP, Grainger JR, Maizels RM. Helminth immunoregulation: the role of parasite secreted proteins in modulating host immunity. Mol Biochem Parasitol. 2009;167:1-11.

17. McSorley HJ, Hewitson JP, Maizels RM. Immunomodulation by helminth parasites: defining mechanisms and mediators. Int J Parasitol. 2013;43:301-10.

18. Buck AH, Coakley G, Simbari F, McSorley HJ, Quintana JF, Le Bihan T, et al. Erratum: exosomes secreted by nematode parasites transfer small RNAs to mammalian cells and modulate innate immunity. Nat Commun. 2015;6:8772.

19. Siles-Lucas M, Morchon R, Simon F, Manzano-Roman R. Exosometransported microRNAs of helminth origin: new tools for allergic and autoimmune diseases therapy? Parasite Immunol. 2015;37:208-14.

20. Cancado GG, Fiuza JA, de Paiva NC, Lemos Lde C, Ricci ND, Gazzinelli-Guimaraes PH, et al. Hookworm products ameliorate dextran sodium sulfateinduced colitis in BALB/c mice. Inflamm Bowel Dis. 2011;17:2275-86.

21. Wang L, Yu Z, Wan S, Wu F, Chen W, Zhang B, et al. Exosomes derived from dendritic cells treated with Schistosoma japonicum soluble egg antigen attenuate DSS-induced colitis. Front Pharmacol. 2017;8:651.

22. Liu F, Cheng W, Pappoe F, Hu X, Wen H, Luo Q, et al. Schistosoma japonicum cystatin attenuates murine collagen-induced arthritis. Parasitol Res. 2016;115:3795-806

23. Yang $X$, Liu J, Yue Y, Chen W, Song M, Zhan X, et al. Cloning, expression and characterisation of a type II cystatin from Schistosoma japonicum, which could regulate macrophage activation. Parasitol Res. 2014;113:3985-92.

24. Jang SW, Cho MK, Park MK, Kang SA, Na BK, Ahn SC, et al. Parasitic helminth cystatin inhibits DSS-induced intestinal inflammation via lL-10(+) F4/80(+) macrophage recruitment. Korean J Parasitol. 2011;49:245-54.

25. Schnoeller C, Rausch S, Pillai S, Avagyan A, Wittig BM, Loddenkemper C, et al. A helminth immunomodulator reduces allergic and inflammatory responses by induction of IL-10-producing macrophages. J Immunol. 2008; 180:4265-72.

26. He B, Cai G, Ni Y, Li Y, Zong H, He L. Characterization and expression of a novel cystatin gene from Schistosoma japonicum. Mol Cell Probes. 2011;25:186-93.

27. Chen L, He B, Hou W, He L. Cysteine protease inhibitor of Schistosoma japonicum - a parasite-derived negative immunoregulatory factor. Parasitol Res. 2017;116:901-8.

28. Semeniuk LM, Kryski AJ, Severson DL. Echocardiographic assessment of cardiac function in diabetic $\mathrm{db} / \mathrm{db}$ and transgenic $\mathrm{db} / \mathrm{db}-\mathrm{hGLUT4}$ mice. Am J Physiol Heart Circ Physiol. 2002;283:H976-82.

29. Chen ZB, Tang H, Liang YB, Yang W, Wu JG, Hu XC, et al. Recombinant Trichinella spiralis 53-kDa protein activates M2 macrophages and attenuates the LPS-induced damage of endotoxemia. Innate Immun. 2016;22:419-32

30. Jia L, Wang Y, Wang Y, Ma Y, Shen J, Fu Z, et al. Heme oxygenase-1 in macrophages drives septic cardiac dysfunction via suppressing lysosomal degradation of inducible nitric oxide synthase. Circ Res. 2018;122:1532-44.

31. Cheng Y, Yang C, Luo D, Li X, Le XC, Rong J. N-propargyl caffeamide skews macrophages towards a resolving $\mathrm{M} 2$-like phenotype against myocardial ischemic injury via activating Nrf2/HO-1 pathway and inhibiting NF-KB pathway. Cell Physiol Biochem. 2018;47:2544-57.

32. Elst KM, Spapen HD, Nguyen DN, Garbar C, Huyghens LP, Gorus FK. Cardiac troponins I and T are biological markers of left ventricular dysfunction in septic shock. Clin Chem. 2000;46:650-7.

33. Tettamanti C, Hervet T, Grabherr S, Palmiere C. Elevation of NT-proBNP and cardiac troponins in sepsis-related deaths: a forensic perspective. Int J Legal Med. 2016;130:1035-43.
34. Xie J, Zhang L, Fan X, Dong X, Zhang Z, Fan W. MicroRNA-146a improves sepsis-induced cardiomyopathy by regulating the TLR-4/NF-kappaB signaling pathway. Exp Ther Med. 2019;18:779-85.

35. Bai T, Hu X, Zheng Y, Wang S, Kong J, Cai L. Resveratrol protects against lipopolysaccharide-induced cardiac dysfunction by enhancing SERCA2a activity through promoting the phospholamban oligomerization. Am J Physiol Heart Circ Physiol. 2016;311:H1051-62.

36. Alves-Filho JC, de Freitas A, Spiller F, Souto FO, Cunha FQ. The role of neutrophils in severe sepsis. Shock. 2008;30:3-9.

37. Abulizi P, Loganathan N, Zhao D, Mele T, Zhang Y, Zwiep T, et al. Growth differentiation factor-15 deficiency augments inflammatory response and exacerbates septic heart and renal injury induced by lipopolysaccharide. Sci Rep. 2017;7:1037.

38. Sanchez-Villamil JP, D'Annunzio V, Finocchietto P, Holod S, Rebagliati I, Perez $\mathrm{H}$, et al. Cardiac-specific overexpression of thioredoxin 1 attenuates mitochondrial and myocardial dysfunction in septic mice. Int J Biochem Cell Biol. 2016;81:323-34.

39. Lang A, Horler D, Baici A. The relative importance of cysteine peptidases in osteoarthritis. J Rheumatol. 2000;27:1970-9.

40. Turk V, Turk B, Turk D. Lysosomal cysteine proteases: facts and opportunities. EMBO J. 2001;20:4629-33.

41. Honey K, Rudensky AY. Lysosomal cysteine proteases regulate antigen presentation. Nat Rev Immunol. 2003;3:472-82.

42. Nixon RA, Cataldo AM, Mathews PM. The endosomal-lysosomal system of neurons in Alzheimer's disease pathogenesis: a review. Neurochem Res. 2000;25:1161-72

43. Kos J, Lah TT. Cysteine proteinases and their endogenous inhibitors: target proteins for prognosis, diagnosis and therapy in cancer (review). Oncol Rep. 1998;5:1349-61.

44. Wang $S$, Xie Y, Yang X, Wang X, Yan K, Zhong Z, et al. Therapeutic potential of recombinant cystatin from Schistosoma japonicum in TNBS-induced experimental colitis of mice. Parasit Vectors. 2016;9:6.

45. Sanfilippo F, Corredor C, Arcadipane A, Landesberg G, Vieillard-Baron A, Cecconi $\mathrm{M}$, et al. Tissue Doppler assessment of diastolic function and relationship with mortality in critically ill septic patients: a systematic review and meta-analysis. Br J Anaesth. 2017;119:583-94.

46. Dragoi Galrinho R, Ciobanu AO, Rimbas RC, Manole CG, Leena BM, Vinereanu D. New echocardiographic protocol for the assessment of experimental myocardial infarction in rats. Maedica (Buchar). 2015;10:85-90.

47. Cameli M, Mandoli GE, Loiacono F, Dini FL, Henein M, Mondillo S. Left atrial strain: a new parameter for assessment of left ventricular filling pressure. Heart Fail Rev. 2016;21:65-76.

48. Han D, Li X, Li S, Su T, Fan L, Fan WS, et al. Reduced silent information regulator 1 signaling exacerbates sepsis-induced myocardial injury and mitigates the protective effect of a liver $X$ receptor agonist. Free Radic Biol Med. 2017;113:291-303.

49. Arlati S, Brenna S, Prencipe L, Marocchi A, Casella GP, Lanzani M, et al. Myocardial necrosis in ICU patients with acute non-cardiac disease: a prospective study. Intensive Care Med. 2000;26:31-7.

50. Burg ND, Pillinger $M H$. The neutrophil: function and regulation in innate and humoral immunity. Clin Immunol. 2001:99:7-17.

51. Klebanoff SJ. Myeloperoxidase: friend and foe. J Leukoc Biol. 2005:77:598-625.

52. Romson JL, Hook BG, Kunkel SL, Abrams GD, Schork MA, Lucchesi BR. Reduction of the extent of ischemic myocardial injury by neutrophil depletion in the dog. Circulation. 1983;67:1016-23.

53. Hotchkiss RS, Karl IE. The pathophysiology and treatment of sepsis. N Engl J Med. 2003;348:138-50.

54. Dorge H, Schulz R, Belosjorow S, Post H, van de Sand A, Konietzka I, et al. Coronary microembolization: the role of TNF-alpha in contractile dysfunction. J Mol Cell Cardiol. 2002;34:51-62.

55. Lv S, Han M, Yi R, Kwon S, Dai C, Wang R. Anti-TNF-alpha therapy for patients with sepsis: a systematic meta-analysis. Int I Clin Pract. 2014;68:520-8.

56. Tripsianis G, Papadopoulou E, Anagnostopoulos K, Botaitis S, Katotomichelakis M, Romanidis K, et al. Coexpression of IL-6 and TNF-alpha: prognostic significance on breast cancer outcome. Neoplasma. 2014;61:205-12.

57. Hua F, Li CH, Wang H, Xu HG. Relationship between expression of COX-2, TNF-alpha, IL-6 and autoimmune-type recurrent miscarriage. Asian Pac J Trop Med. 2013;6:990-4. 
58. Turdi S, Han X, Huff AF, Roe ND, Hu N, Gao F, et al. Cardiac-specific overexpression of catalase attenuates lipopolysaccharide-induced myocardial contractile dysfunction: role of autophagy. Free Radic Biol Med. 2012;53:1327-38.

59. Smallwood TB, Giacomin PR, Loukas A, Mulvenna JP, Clark RJ, Miles JJ. Helminth immunomodulation in autoimmune disease. Front Immunol. 2017;8:453.

60. Scumpia PO, Moldawer LL. Biology of interleukin-10 and its regulatory roles in sepsis syndromes. Crit Care Med. 2005;33:S468-71.

61. Hunter MM, Wang A, Parhar KS, Johnston MJ, Van Rooijen N, Beck PL, et al. In vitro-derived alternatively activated macrophages reduce colonic inflammation in mice. Gastroenterology. 2010;138:1395-405.

62. Faz-López B, Morales-Montor J, Terrazas LI. Role of macrophages in the repair process during the tissue migrating and resident helminth infections. Biomed Res Int. 2016;2016:8634603.

63. Tan S, Long Z, Hou X, Lin Y, Xu J, You X, et al. H2 protects against lipopolysaccharide-induced cardiac dysfunction via blocking TLR4-Mediated cytokines expression. Front Pharmacol. 2019;10:865.

64. Williams DL, Ha T, Li C, Kalbfleisch JH, Schweitzer J, Vogt W, et al. Modulation of tissue toll-like receptor 2 and 4 during the early phases of polymicrobial sepsis correlates with mortality. Crit Care Med. 2003;31:1808-18.

65. Feng Y, Zou L, Zhang M, Li Y, Chen C, Chao W. MyD88 and Trif signaling play distinct roles in cardiac dysfunction and mortality during endotoxin shock and polymicrobial sepsis. Anesthesiology. 2011;115:555-67.

66. Avlas O, Fallach R, Shainberg A, Porat E, Hochhauser E. Toll-like receptor 4 stimulation initiates an inflammatory response that decreases cardiomyocyte contractility. Antioxid Redox Signal. 2011;15:1895-909.

67. Kawai T, Akira S. Signaling to NF-kappaB by toll-like receptors. Trends Mol Med. 2007;13:460-9.

68. Fernandes C J Jr, de Assuncao MS. Myocardial dysfunction in sepsis: a large, unsolved puzzle. Crit Care Res Pract. 2012;2012:896430.
69. Cain BS, Meldrum DR, Dinarello CA, Meng X, Joo KS, Banerjee A, et al. Tumor necrosis factor-alpha and interleukin-1 beta synergistically depress human myocardial function. Crit Care Med. 1999;27:1309-18.

70. Puneet P, McGrath MA, Tay HK, Al-Riyami L, Rzepecka J, et al. Retraction: The helminth product ES-62 protects against septic shock via toll-like receptor 4-dependent autophagosomal degradation of the adaptor MyD88. Nat Immunol. 2011;12:804.

71. Du L, Liu L, Yu Y, Shan H, Li L. Trichinella spiralis excretory-secretory products protect against polymicrobial sepsis by suppressing MyD88 via mannose receptor. Biomed Res Int. 2014;2014:898646.

72. Turner JD, Langley RS, Johnston KL, Egerton G, Wanji S, Taylor MJ. Wolbachia endosymbiotic bacteria of Brugia malayi mediate macrophage tolerance to TLR- and CD40-specific stimuli in a MyD88/TLR2-dependent manner. J Immunol. 2006;177:1240-9.

73. Martin I, Caban-Hernandez K, Figueroa-Santiago O, Espino AM. Fasciola hepatica fatty acid binding protein inhibits TLR4 activation and suppresses the inflammatory cytokines induced by lipopolysaccharide in vitro and in vivo. J Immunol. 2015;194:3924-36.

\section{Publisher's Note}

Springer Nature remains neutral with regard to jurisdictional claims in published maps and institutional affiliations.
Ready to submit your research? Choose BMC and benefit from:

- fast, convenient online submission

- thorough peer review by experienced researchers in your field

- rapid publication on acceptance

- support for research data, including large and complex data types

- gold Open Access which fosters wider collaboration and increased citations

- maximum visibility for your research: over 100M website views per year

At BMC, research is always in progress.

Learn more biomedcentral.com/submissions 